\title{
MUSCULOSKELETAL SYMPTOMS AND EXPOSURE TO WHOLE-BODY VIBRATION AMONG OPEN-PIT MINE WORKERS IN THE ARCTIC
}

\section{LAGE BURSTRÖM ${ }^{1,2}$, ANNA AMINOFF $^{3}$, BODIL BJÖR ${ }^{1,2}$, SATU MÄNTTÄRI ${ }^{4}$, TOHR NILSSON $^{1,2}$, HANS PETTERSSON ${ }^{1,2}$, HANNU RINTAMÄKI ${ }^{4}$, INGEMAR RÖDIN ${ }^{3,5}$, VICTOR SHILOV $^{6}$, LJUDMILA TALYKOVA $^{6}$, ARILD VAKTSKJOLD ${ }^{7,8}$, and JENS WAHLSTRÖM ${ }^{1,2}$}

${ }^{1}$ Umeå University, Umeå, Sweden

Department of Public Health and Clinical Medicine, Occupational and Environmental Medicine

${ }^{2}$ Umeå University, Arcum, Umeå, Sweden

${ }^{3}$ University Hospital of North Norway, Troms $\emptyset$, Norway

Department of Occupational and Environmental Medicine

${ }^{4}$ Finnish Institute of Occupational Health, Oulu, Finland

${ }^{5}$ Swedish Work Environment Authority, Stockholm, Sweden

${ }^{6}$ Northwest Public Health Research Center, St. Petersburg, Russia

${ }^{7}$ Hedmark University of Applied Sciences, Elverum, Norway

Department of Public Health

${ }^{8}$ Innlandet Hospital Trust, Brumunddal, Norway

Department of Research

\begin{abstract}
Objectives: This cross-sectional questionnaire study was carried out at 4 open-pit mines in Finland, Norway, Russia and Sweden as part of the MineHealth project. The aim has been to compare the prevalence of musculoskeletal symptoms between drivers of mining vehicles and non-drivers. Material and Methods: The mine workers were asked whether they had suffered from any musculoskeletal symptoms during the previous 12 months in specified body regions, and to grade the severity of these symptoms during the past month. They were also asked about their daily driving of mining vehicles. Results: The questionnaire was completed by 1323 workers ( 757 vehicle drivers) and the reported prevalence and severity of symptoms were highest for the lower back, followed by pain in the neck, shoulder and upper back. Drivers in the Nordic mines reported fewer symptoms than non-drivers, while for Russian mine workers the results were the opposite of that. The daily driving of mining vehicles had no significant association with the risk of symptoms. Female drivers indicated a higher prevalence of symptoms as compared to male drivers. Conclusions: The study provided only weak support for the hypothesis that drivers of vehicles reported a higher prevalence of musculoskeletal symptoms than non-vehicle drivers. There were marked differences in the prevalence of symptoms among workers in various enterprises, even though the nature of the job tasks was similar. Int J Occup Med Environ Health 2017;30(4):553-564
\end{abstract}

\section{Key words:}

Questionnaire, Mining, Vibration, MSD, Whole-body, Barents

Funding: this work was carried out with the financial assistance of the European Union (Kolarctic ENPI CBC 02/2011/043/KO303 - MineHealth, project manager: Assoc. Prof. Lage Burström), and FORTE (Swedish Research Council for Health, Working Life and Welfare 2011-0494, project manager: Assoc. Prof. Lage Burström). The contents of this manuscript are the sole responsibility of the authors, and under no circumstances can they be regarded as reflecting the position of the European Union or FORTE. Received: March 23, 2016. Accepted: June 13, 2016.

Corresponding author: L. Burström, Umeå University, Department of Public Health and Clinical Medicine, Occupational and Environmental Medicine, SE-901 87 Umeå, Sweden (e-mail: lage.burstrom@umu.se). 


\section{INTRODUCTION}

Long-term occupational exposure to whole-body vibration (WBV) is associated with an increased prevalence of self-reported musculoskeletal symptoms, especially low back pain (LBP) [1-3]. The contribution of WBV to those health problems is not fully understood, and it appears that the occurrence and severity of musculoskeletal symptoms is influenced by several factors, such as the nature of exposure to vibration, type of machinery and work process, environmental conditions, and biodynamic and ergonomic factors [4-6]. A number of individual characteristics, such as age and smoking [7], height and weight [8] and mental stress [9], have also been associated with musculoskeletal symptoms. Operators of vehicles used in mining operations are exposed to considerable WBV during relatively long work periods [10-15]. Studies have also shown that the prevalence of self-reported musculoskeletal symptoms is higher among drivers of mine vehicles than among nonexposed workers [16,17]. In recent years it has become more common for females to be employed in the mining industry. However, there is a lack of information on the health risks posed by WBV among female workers [18]. Moreover, there is a lack of studies comparing the levels of selfreported musculoskeletal symptoms among WBV-exposed populations at various mines and countries, and above all at mines situated in the Barents region.

The aim of this study has been to compare the prevalence and severity of musculoskeletal symptoms among drivers of mining vehicles with non-drivers in a study group of male and female mine workers in the Barents region.

\section{MATERIAL AND METHODS}

This cross-sectional study was carried out at 4 open-pit mines in Finland, Norway, Russia and Sweden over the period from November 2012 to November 2013. The mines were located in the Finnish Lapland, Finnmark County in Norway, Kola Peninsula in Russia and in the Swedish Lapland [19]. All the mines are located in the Barents region between the latitudes of $67^{\circ} \mathrm{N}$ and $71^{\circ} \mathrm{N}$. At the mines in Finland, Russia and Sweden, mining operations continue throughout the year, while at the mine in Norway there is no activity in the open pit during the winter period. The total number of employees at the various mines was around 4400 (in Finland approx. 200, in Norway approx. 110, in Russia approx. 3500, in Sweden approx. 600). The group of mine workers included in the study represents all the different occupations at the mines in question, with the main groups being vehicle drivers, mechanics, electricians and foremen. In the mines there are typical mine vehicle used like haul trucks, drilling rigs, wheel loaders, excavators, dozers, graders and transport cars. The mine vehicles are comparable among the mines, even though they represent different manufacturers, models, and capacity.

The study participants completed a questionnaire that had been developed as a part of the MineHealth project [20] and translated into each country's native language. The questionnaire [21] was based on the Nordic questionnaire [22], the VIBRISKS (Risks of Occupational Vibration Injuries) questionnaire [23] and the "Workers' Health 2010" questionnaire [17]. The questionnaire covered basic information such as age, sex, weight, height and smoking. It also covered workers' personal, work and health experiences. The mine workers were asked "if they had suffered from any musculoskeletal symptoms, including ache, pain or discomfort during the previous 12 months" in the body regions, and were given the alternatives of "yes" or "no." The mine workers were also asked "to grade the severity of the symptoms" in the regions of the body where they had experienced symptoms during the past month on a category scale of none, mild, moderate, severe and extreme. Stress was measured using the question: "Stress means a situation in which a person feels tense, restless, nervous or anxious or is unable to sleep at night because a person's mind is troubled all the time. Have you felt this kind of stress during the last month on a scale of: not at all, only a little, somewhat, rather a lot, a great deal?" [24]. The mine workers were also 
asked about their work shift schedules and daily driving in terms of hours and various types of mining vehicles, such as load haul trucks, haul trucks, drilling rigs, wheel loaders and excavators. The study was approved by the regional committees for medical research in each of the countries.

All calculations were performed using the statistical program SPSS v. 23 (IBM Corp, 2015). The information about the mine workers' shift schedules was used for calculating the individual mean daily hours spent driving a mining vehicle. The questions regarding the severity of the symptoms associated with work during the past month were dichotomized, with the first 2 answers considered to be low and the other 3 answers considered to be of substantial intensity. The same categorization was made for the question related to stress. The used definition for "driver of mining vehicle" was that the mine worker should have reported daily driving for more than $5 \mathrm{~min}$. All other workers were regarded as nondrivers. The daily use of a vehicle was divided into short and long daily exposure times based on the median value for each mine. The binary logistic-regression analysis was used for analyzing any associations (odds ratio (OR) between subjective reported symptoms and the use of a mining vehicle. An OR greater than 1 indicates a higher risk in the exposed group as compared to the unexposed group. In the analyses, the male mine workers in Finland, Norway and Sweden were grouped together as Nordic mine workers. The analysis also considered male and female workers separately, with the gender difference in symptoms analyzed by an independent $t$-test.

\section{RESULTS}

The questionnaire was completed by 1323 workers who had agreed to participate. The characteristics of the workers in the different mines are given in the Table 1.

The mean age of participating mine workers was 40 years old (Table 1), and $57 \%$ of the workers were drivers of various mining vehicles, with the mean daily driving time of about $4.3 \mathrm{~h}$. The proportion of those who reported smoking varied from $14 \%$ in Sweden to $46 \%$ in Russia.
The corresponding proportion that reported stress levels above "only a little" varied from $16 \%$ in Russia to $42 \%$ in Finland. Female mine workers were younger than male mine workers and reported a higher percentage of stress above "only a little" than male mine workers.

The prevalence of reported symptoms during the previous 12 months in the specific body regions is shown in the Table 2, grouped by mine and gender. The table also shows the prevalence of answers above "substantial intensity" with regard to the severity of the symptoms in the same body regions during the past month.

The 12-month prevalence of symptoms in the specific body regions varied between $13 \%$ and $49 \%$ for all mine workers. The corresponding 1-month prevalence of substantial severity of symptoms was found to be between $8 \%$ and $28 \%$. The results also show that there were some differences in the occurrence of the ratings between mines and genders for both the 12-month prevalence of symptoms and the severity of symptoms during the past month. For instance, the proportion of those reporting LBP varied from $43 \%$ in Russia to $67 \%$ in Norway. In general, there was a lower occurrence and less severity of symptoms among Russian mine workers than among the mine workers from the other mines. Male mine workers reported a significantly lower occurrence of symptoms during the previous 12 months as compared to female mine workers $(0.01<\mathrm{p}<0.02)$ for all body regions except for the elbow. The corresponding 1-month prevalence of substantial severity of symptoms among females was also found to be significantly higher $(0.01<\mathrm{p}<0.02)$ for the neck, shoulder, lower back and hip.

\section{Drivers of vehicles vs. non drivers}

The number of workers using a vehicle was 757 (male: 692, female: 65 ) and the mean exposure time per day was $7.5 \mathrm{~h}$ (standard deviation $(\mathrm{SD})=3.6, \min .=0.1, \max =12$ ). The Russian mine vehicles drivers had a significantly $(\mathrm{p}<0.01)$ longer exposure time than Nordic drivers (8.9 h vs. 5.1 h). In general, males had a longer exposure 


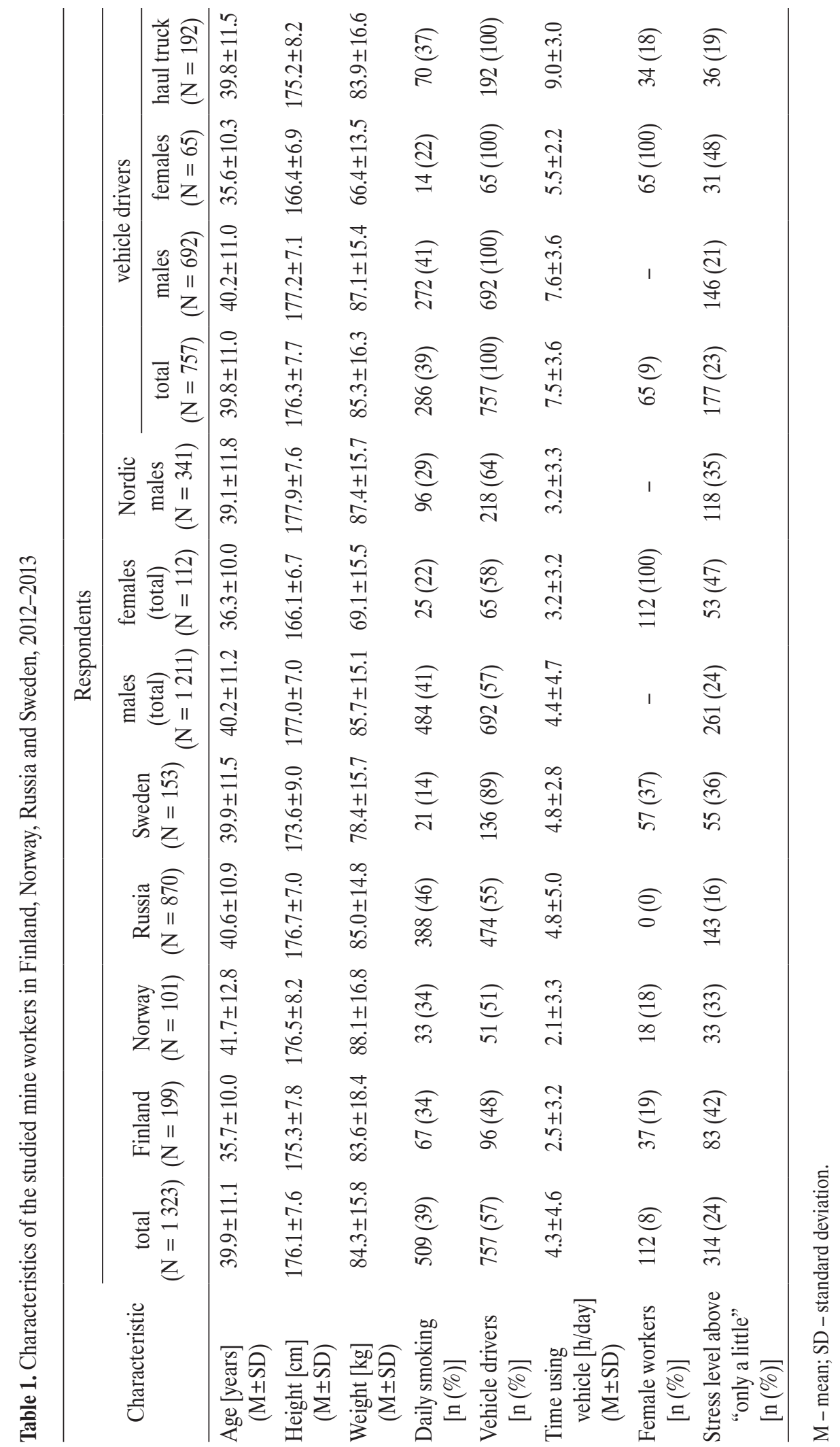


Table 2. Prevalence of symptoms in the specific body regions among the studied mine workers in Finland, Norway, Russia and Sweden, 2012-2013

\begin{tabular}{|c|c|c|c|c|c|c|c|}
\hline \multirow{2}{*}{ Occurrence of symptoms } & \multicolumn{7}{|c|}{$\begin{array}{c}\text { Respondents } \\
{[\%]}\end{array}$} \\
\hline & total & Finland & Norway & Russia & Sweden & $\begin{array}{c}\text { Nordic } \\
\text { males }\end{array}$ & $\begin{array}{l}\text { Nordic } \\
\text { females }\end{array}$ \\
\hline \multicolumn{8}{|l|}{ During the previous 12 months } \\
\hline neck & 40 & 59 & 55 & 31 & 59 & 52 & 78 \\
\hline shoulder & 34 & 62 & 50 & 23 & 56 & 50 & 80 \\
\hline elbow & 18 & 18 & 20 & 19 & 13 & 17 & 17 \\
\hline wrist/hand & 20 & 35 & 32 & 15 & 25 & 30 & 33 \\
\hline upper back & 34 & 32 & 34 & 35 & 32 & 27 & 50 \\
\hline lower back & 49 & 59 & 67 & 43 & 66 & 60 & 74 \\
\hline hip & 12 & 15 & 30 & 8 & 22 & 16 & 36 \\
\hline knee & 26 & 38 & 46 & 20 & 33 & 37 & 42 \\
\hline ankle/foot & 13 & 21 & 23 & 11 & 12 & 18 & 21 \\
\hline \multicolumn{8}{|l|}{$\begin{array}{l}\text { Of substantial intensity during } \\
\text { the previous month }\end{array}$} \\
\hline neck & 23 & 23 & 38 & 19 & 34 & 26 & 41 \\
\hline shoulder & 20 & 26 & 37 & 15 & 29 & 25 & 41 \\
\hline elbow* & 8 & 7 & 13 & & 7 & 8 & 11 \\
\hline wrist/hand & 12 & 10 & 17 & 12 & 12 & 12 & 14 \\
\hline upper back* & 26 & 33 & 25 & & 19 & 24 & 34 \\
\hline lower back & 28 & 14 & 49 & 27 & 35 & 27 & 37 \\
\hline hip* & 11 & 6 & 18 & & 13 & 7 & 22 \\
\hline knee & 17 & 20 & 26 & 15 & 23 & 23 & 21 \\
\hline ankle/foot & 9 & 8 & 15 & 9 & 6 & 9 & 6 \\
\hline
\end{tabular}

* Question not asked in Russia.

time as compared to females (7.6 h vs. $5.5 \mathrm{~h}, \mathrm{p}<0.01)$. When comparing only Nordic mine workers, female drivers had a slightly longer exposure time than males (5.5 h vs. 5 h, $\mathrm{p}=0.16$ ).

The prevalence of symptoms during the previous 12 months in the specific body regions is summarized in the Table 3 for drivers of vehicles as compared to non-drivers. The table also shows the prevalence of answers for substantial severity of the symptoms in the same body regions during the past month. The results are also divided in terms of male and female mine workers. The table also gives the corresponding information for the 192 haul truck drivers (male Nordic $(\mathrm{N}=51)$, male Russian ( $\mathrm{N}=107)$, female Nordic $(\mathrm{N}=34)$ ).

For workers in the Nordic mines - both males and females - there is a slight tendency for drivers of vehicles to report fewer symptoms than non-drivers. In the case of the Russian mine workers (male only), the results seem to be the other way round. For drivers of haul trucks, the occurrence and severity of symptoms are in general lower than for other groups of drivers.

Detailed results of the statistical analyses of the occurrence and severity of symptoms are given in the Table 4 . 


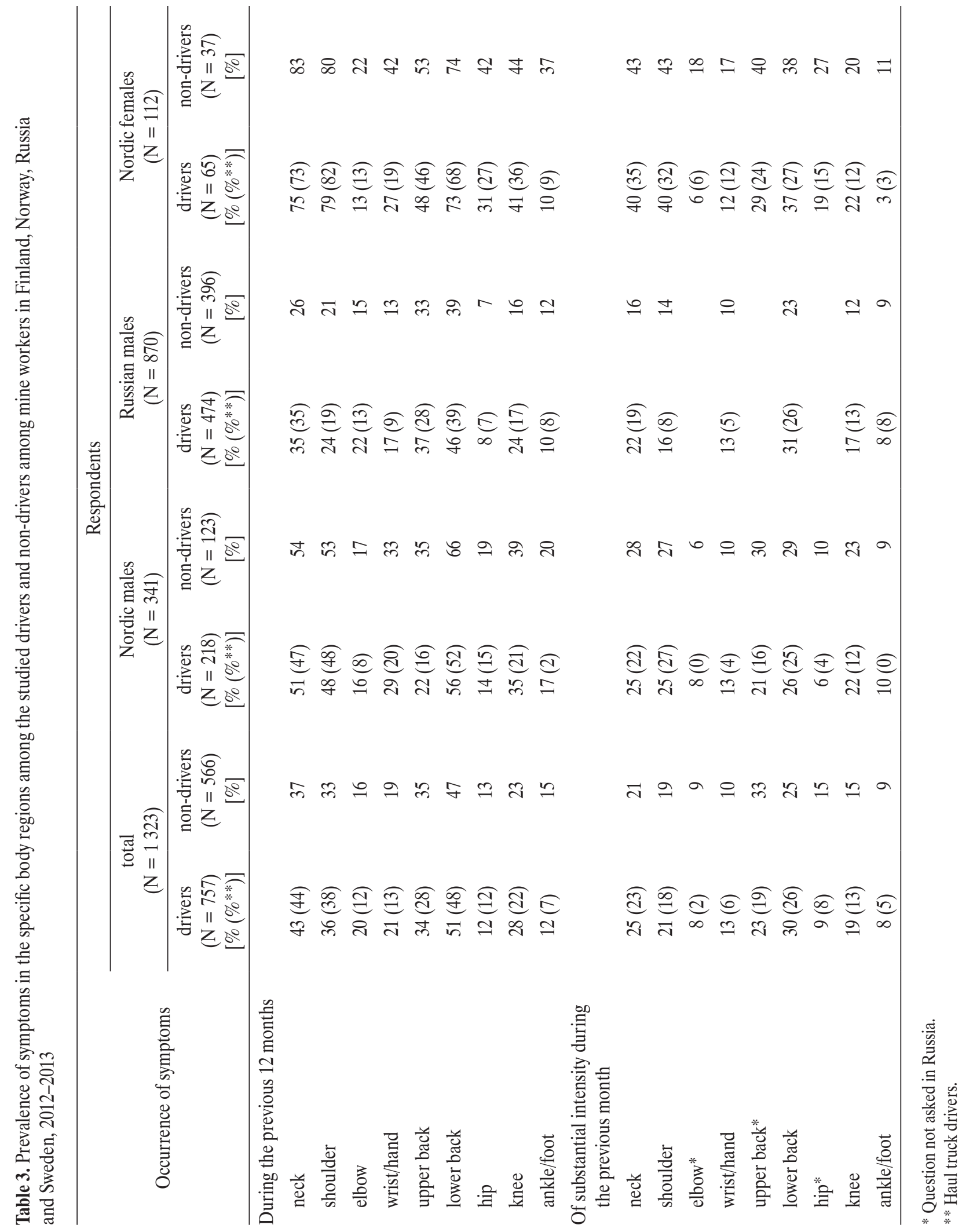




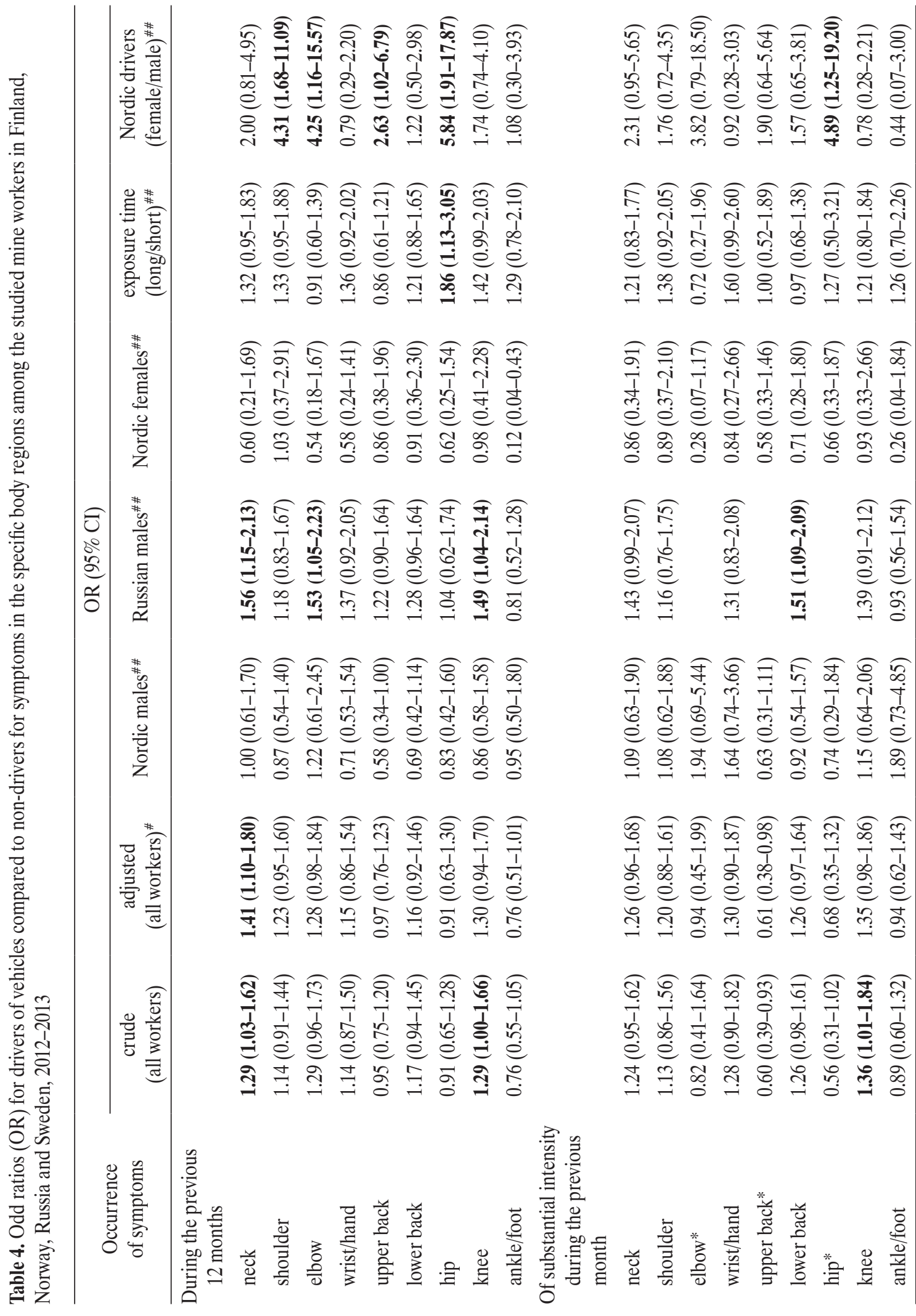

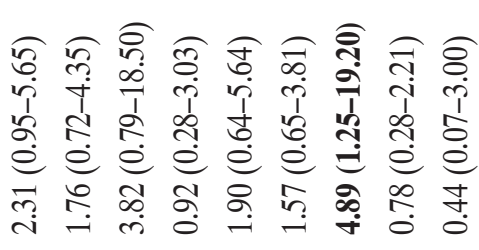

통응

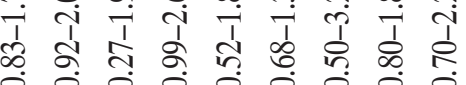

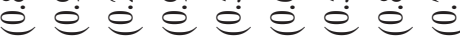

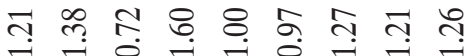

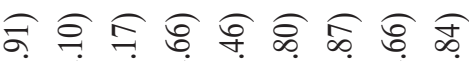

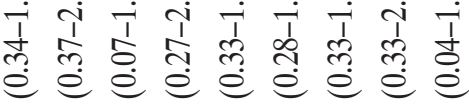
品

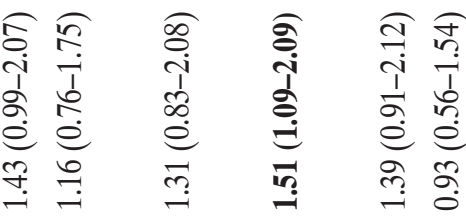

क्षे

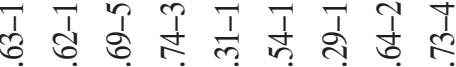
e e e e e e e e

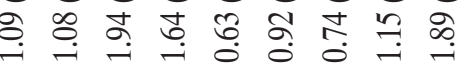

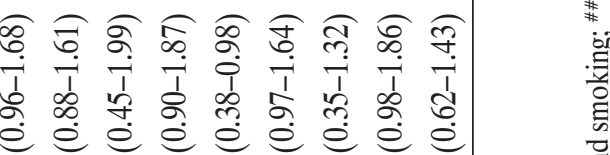

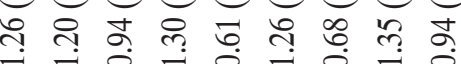

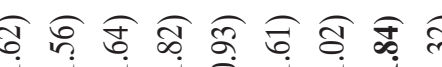

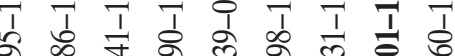
e e e e é e é巳

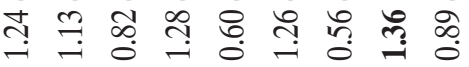
흔

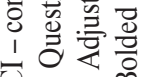


The table also shows the relation to the outcomes for short $(\mathrm{N}=313)$ and long exposure times $(\mathrm{N}=444)$, as well as for Nordic male $(\mathrm{N}=218)$ and female $(\mathrm{N}=65)$ drivers of vehicles.

The results show small differences in the crude and adjusted OR for the outcomes, occurrence and severity of symptoms, in comparison to drivers of vehicles and nondrivers. In the case of drivers of vehicles, the results indicate an increased OR for all body regions except for the upper back, hip and ankle, although this is not always significant. Separate analyses of Nordic and Russian male mine workers show that the only significantly higher ORs for some body regions that could be identified are among Russian mine workers when comparing drivers of vehicles to non-drivers. In the case of female mine workers, no increase in ORs due to the use of a vehicle could be found. The calculation between long and short daily exposure times indicates an increased OR for longer exposure time, although this is not significant. The comparison between Nordic female and male drivers indicates a significant increase in OR for the shoulder, elbow, upper back and hip among females.

\section{DISCUSSION}

In our cross-sectional survey of mine workers in the Barents area, the reported prevalence of symptoms during the previous 12 months was highest for the lower back, with a prevalence of $49 \%$. The second most common was pain in the neck (40\%), followed by shoulder (34\%) and upper back (34\%). A similar pattern was found for the severity of symptoms during the past month. The populations investigated were more or less comparable in terms of mean age, height and weight. However, there were some pronounced differences between the mines in reported smoking habits and the reported levels of stress. There were also pronounced differences between the mines in terms of vehicle use and the mean time spent driving a vehicle. The reason for the absence of Russian female mine workers in the study was the restriction placed on female workers; Russian labor legislation stipulating that female workers are not allowed to perform hard work or work in harmful or dangerous conditions [25]. In the Russian mine, female workers (about $10 \%$ of the total number of employees) are therefore employed in other occupations than mine work [17] and these occupations were not invited to take part in the study.

The results of the study have provided only weak support for the hypothesis that drivers of vehicles experience more musculoskeletal symptoms than non-drivers. If driving a vehicle is assumed to be a valid indicator of exposure to WBV, one conclusion would be that WBV might not increase the risk of developing symptoms or increase the severity of musculoskeletal symptoms. This conclusion is supported to some small extent by the comparison between short and long exposure times, which indicates only an insignificant tendency towards an exposure-response relationship. The differences in work load between the exposed and non-exposed groups may be considerable at times, though no attempts have been made to control for such differences by taking into account various influencing and ergonomically confounding factors.

Several studies have reported a higher incidence of musculoskeletal symptoms among female drivers as compared to male drivers [26-28]. The same tendency has been found in this study, even within the same profession where workers have exactly the same duties, such as drivers of load haul trucks. The reasons for gender differences in reported symptoms have been extensively discussed, and Fillingim et al. [29] have concluded that the scientific findings from studies of musculoskeletal symptoms indicate that, regardless of site or time frame, females are consistently more likely to report musculoskeletal symptoms than males, though these differences may be less consistent in the case of LBP. However, the comparison between female and male drivers which has indicated a significant increase in the adjusted OR for the shoulder, elbow, upper 
back and hip for females could also be interpreted as an impact resulting from the design of the vehicle environments which perhaps are more suited to a male physical frame. This could result in a higher work load for female drivers as compared to male drivers although they have the same occupation and the same working task, too.

Mining in the Barents region is influenced by its characteristic environmental conditions, such as major fluctuations in temperature, with cold, snowy winters and warm, light summers. It has already been pointed out that working in a cold climate is a factor that may cause an increase in musculoskeletal symptoms [30]. In our study we have observed that the most prevalent body site for musculoskeletal symptoms has been the low back, and this has affected $51 \%$ of drivers of mining vehicles who have reported occurrence of the symptoms over 12 months (Russian males $-46 \%$, Nordic males $-56 \%$, Nordic females $-73 \%$ ). Although the results of previous studies of mining vehicles drivers are scarce, Bovenzi et al. [18] have reported a $58 \%$ prevalence of 12-month LBP among mine workers in marble quarries in Italy, and Mandal and Srivastava [16] have reported a corresponding figure of $85 \%$ for LBP among Indian dumper operators.

In the case of female mining vehicle drivers, no previous studies have been conducted that have reported on the prevalence of musculoskeletal symptoms. A review of the available literature has shown that the range of the prevalence of musculoskeletal disorders affecting the lower back among drivers of different vehicles varies widely, from $30 \%$ to $85 \%$, between the studies carried out $[1,2]$. The discrepancies between the studies of professional drivers might be due to differences in the design of the study, the characteristics of the study populations and the definition of LBP outcomes. Our results, therefore, do not provide any evidence to suggest an association between drivers working in a cold climate and an increased risk of musculoskeletal complaints. One important reason may be that drivers of vehicles are normally protected from the outdoor climate while in the cabin, and the time they spend outdoors using protective clothing is limited. Our results also show marked differences in the symptom prevalence between Nordic and Russian mine workers. In general, mine workers in the Nordic mines have the highest period prevalence of symptoms as well as severity of symptoms, while Russian mine workers have the lowest. The same pattern has also been found for well-defined occupations such as drivers of load haul trucks, who basically run the same types of machines in all the mines. This increase in prevalence, which is sometimes almost two-fold, is difficult to explain since both methodological (the potential for bias in worker recruitment and sample selection between different enterprises, in particular) and real and changeable causes are plausible [7].

There may be a language bias because symptoms are understood differently in different languages and cultures. Thus, despite the care we took, in translation the term "symptoms" may not have meant the same to all the participants in our study. The method of translation of the English - written questionnaire into the various native languages has not been standardized, involving 2 or more independent translators familiar with the terminology of the questionnaire. One argument for why the language bias might not have influenced the results is that the prevalence of self-reported complaints in the elbow and upper back is much the same in all the mines. In addition, cultural differences in terms of the threshold of reporting symptoms and in viewing the stigma of disease may have been a source of bias. However, these results have not been compared to the outcome of the clinical examinations carried out in the mines. Therefore, we do not think that the observed differences in reported symptoms can be explained simply by divergences in the understanding of the questions.

Bias might also have arisen through differential healthy worker selection [31]. If individuals with musculoskeletal disorders had been removed from some occupational 
groups because of their illness, this might have resulted in spuriously low prevalence rates. In Russia, mine workers are summoned to an annual, mandatory medical examination in order to detect early symptoms of disease. However, it seems highly unlikely that such selection would have taken place on a scale sufficiently large to explain the substantial differences in prevalence that were observed.

When stratifying the results for Nordic and Russian mine workers, it is worth noting that driving mining vehicles in Russia has resulted in an increase in the risk of complaints relating to musculoskeletal symptoms as compared to cases in which no driving of vehicles has been involved. However, no such findings could be seen for mine workers from the Nordic mines. The reason is not obvious, and yet again the healthy worker survivor effect may have influenced the results, meaning that there has been an ongoing selection process whereby those who remain employed as drivers tend to be healthier than those who leave such employment. The results from the Nordic mines also indicate that drivers of vehicles report fewer symptoms than non-drivers. One reason may be that symptomatic mine workers in the Nordic mines might be relocated from employment as drivers to other occupations, while in Russia they have to stop working as mine workers. One argument for that could be found in the pronounced difference in prevalence of symptoms between driver and non-driver in Russia. This highlights the importance of selection of "control group" on the calculated risks. Another potential bias in our study and in our analyses of the data is that we have not taken into account the number of years of employment as a miner or drivers' actual exposure to vibrations in terms of measured vibration exposure and objectively established exposure time.

A cross-sectional survey such as ours cannot establish the extent to which observed associations are causal. In the analyses, we took into consideration both individual factors (sex, age, height, weight) and mental stress, which are known to affect how symptoms are experienced [32], and it may be that these factors have had a greater influence on musculoskeletal symptoms than the investigated exposure to WBV has had.

\section{CONCLUSIONS}

Overall, our findings have provided only weak support for the hypothesis that drivers of vehicles report a higher prevalence of musculoskeletal symptoms in the specific body regions than non-vehicle drivers do. There has also been only an insignificant tendency towards an exposureresponse relationship. Another finding is that there have been marked differences in the prevalence of symptoms between different enterprises, even though the nature of the job task has been similar. Adjustment to personal factors could not explain the differences between Nordic and Russian mine workers. Female drivers in general have had a higher prevalence of musculoskeletal complaints in some body regions as compared to male drivers.

\section{ACKNOWLEDGMENTS}

The authors thank all members of the MineHealth consortium for their work and support.

\section{REFERENCES}

1. Bovenzi M, Hulshof CT. An updated review of epidemiologic studies on the relationship between exposure to whole-body vibration and low back pain (1986-1997). Int Arch Occup Environ Health. 1999;72(6):351-65, https://doi.org/10.1007/ s004200050387.

2. Burström L, Nilsson T, Wahlström J. Whole-body vibration and the risk of low back pain and sciatica: A systematic review and meta-analysis. Int Arch Occup Environ Health. 2015;88(4):403-18, https://doi.org/10.1007/s00420-014-0971-4.

3. Waters T, Rauche C, Genaidy A, Rashed T. A new framework for evaluating potential risk of back disorders due to whole body vibration and repeated mechanical shock. Ergonomics. 2007;50(3):379-95, https://doi.org/10.1080/00140130 601089978 
4. Hoogendoorn WE, van Poppel MN, Bongers PM, Koes BW, Bouter LM. Physical load during work and leisure time as risk factors for back pain. Scand J Work Environ Health. 1999;25(5):387-403, https://doi.org/10.5271/sjweh.451.

5. Hoy J, Mubarak N, Nelson S, de Landas MS, Magnusson M, Okunribido O, et al. Whole body vibration and posture as risk factors for low back pain among forklift truck drivers. J Sound Vib. 2005;284(3-5):933-46, https://doi.org/10.1016/ j.jsv.2004.07.020.

6. Palmer KT, Griffin MJ, Syddall HE, Pannett B, Cooper C, Coggon D. The relative importance of whole body vibration and occupational lifting as risk factors for low-back pain. Occup Environ Med. 2003;60(10):715-21, https://doi. org/10.1136/oem.60.10.715.

7. Coggon D, Ntani G, Palmer KT, Felli VE, Harari R, Barrero LH, et al. Disabling musculoskeletal pain in working populations: Is it the job, the person, or the culture? Pain. 2013; 154(6):856-63, https://doi.org/10.1016/j.pain.2013.02.008.

8. Wahlström J, Burström L, Nilsson T, Järvholm B. Risk factors for hospitalization due to lumbar disc disease. Spine. 2012;37(15):1334-9, https://doi.org/10.1097/BRS.0b013e318 $24 \mathrm{~b} 5464$.

9. Lang J, Ochsmann E, Kraus T, Lang JW. Psychosocial work stressors as antecedents of musculoskeletal problems: A systematic review and meta-analysis of stability-adjusted longitudinal studies. Soc Sci Med. 2012;75(7):1163-74, https:// doi.org/10.1016/j.socscimed.2012.04.015.

10. Howard B, Sesek R, Bloswick D. Typical whole body vibration exposure magnitudes encountered in the open pit mining industry. Work. 2009;34(3):297-303, https:/doi. org/10.3233/WOR-2009-0927.

11. Kumar S. Vibration in operating heavy haul trucks in overburden mining. Appl Ergon. 2004;35(6):509-20, https://doi. org/10.1016/j.apergo.2004.06.009.

12. Salmoni A, Cann A, Gillin K. Exposure to whole-body vibration and seat transmissibility in a large sample of earth scrapers. Work. 2010;35(1):63-75, https://doi.org/10.3233/ WOR-2010-0958.
13. Smets MP, Eger TR, Grenier SG. Whole-body vibration experienced by haulage truck operators in surface mining operations: A comparison of various analysis methods utilized in the prediction of health risks. Appl Ergon. 2010;41(6):76370, https://doi.org/10.1016/j.apergo.2010.01.002.

14. Vanerkar AP, Kulkarni NP, Zade PD, Kamavisdar AS. Whole body vibration exposure in heavy earth moving machinery operators of metalliferrous mines. Environ Monit Assess. 2008;143(1-3):239-45, https://doi.org/10.1007/s10661007-9972-z.

15. Wolfgang R, Burgess-Limerick R. Whole-body vibration exposure of haul truck drivers at a surface coal mine. Appl Ergon. 2014;45(6):1700-4, https://doi.org/10.1016/j.apergo. 2014.05.020.

16. Mandal BB, Srivastava AK. Musculoskeletal disorders in dumper operators exposed to whole body vibration at Indian mines. Int J Min Reclam Environ. 2010;24(3):233-43, https://doi.org/10.1080/17480930903526227.

17. Skandfer M, Talykova L, Brenn T, Nilsson T, Vaktskjold A. Low back pain among mineworkers in relation to driving, cold environment and ergonomics. Ergonomics. 2014;57(10):1541-8, https://doi.org/10.1080/00140139.2014. 904005 .

18. Bovenzi M, Rui F, Negro C, D’Agostin F, Angotzi G, Bianchi $\mathrm{S}$, et al. An epidemiological study of low back pain in professional drivers. J Sound Vib. 2006;298(3):514-39, https:// doi.org/10.1016/j.jsv.2006.06.001.

19. Burström L, Hyvärinen V, Johnsen M, Pettersson H. Exposure to whole-body vibration in open-cast mines in the Barents region. Int J Circumpolar Health. 2016;75(1), https:// doi.org/10.3402/ijch.v75.29373.

20. MineHealth. Final Report. Sustainability of miners' wellbeing, health and work ability in the Barents region A common challenge. MineHealth, March 2012 - December 2014. Working Document No. WP5-D8 [Internet]. Umeå: MineHealth; 2015 [cited 2016 March 22]. Available from: http://minehealth.eu/wp-content/uploads/2015/03/MineHealth_Final_Report-201503231.pdf. 
21. MineHealth. Questionnaire - All questions. Sustainability of miners' well-being, health and work ability in the Barents region - A common challenge. MineHealth. Working Document No. WP2-D.3.1 [Internet]. Umeå: MineHealth; 2012 [cited 2016 March 22]. Available from: http://minehealth.eu/ wp-content/uploads/2013/09/WP2_D3.1.pdf.

22. Kuorinka I, Jonsson B, Kilbom A, Vinterberg H, BieringSorensen F, Andersson G, et al. Standardised Nordic questionnaires for the analysis of musculoskeletal symptoms. Appl Ergon. 1987;18(3):233-7, https://doi.org/10.1016/00036870(87)90010-X.

23. Tiemessen IJ, Hulshof CT, Frings-Dresen MH. Low back pain in drivers exposed to whole body vibration: Analysis of a dose-response pattern. Occup Environ Med. 2008;65(10): 667-75, https://doi.org/10.1136/oem.2007.035147.

24. Elo AL, Leppanen A, Jahkola A. Validity of a single-item measure of stress symptoms. Scand J Work Environ Health. 2003;29(6):444-51, https://doi.org/10.5271/sjweh.752.

25. [Federal Law of 17.07.1999 No. 181-FZ On the basis of protection labor in the Russian Federation]. Russian.

26. Barnekow-Bergkvist M, Hedberg GE, Janlert U, Jansson E. Determinants of self-reported neck-shoulder and low back symptoms in a general population. Spine. 1998;23(2):235-43, https://doi.org/10.1097/00007632-199801150-00017.

27. Hagberg M, Burström L, Ekman A, Vilhelmsson R. The association between whole body vibration exposure and musculoskeletal disorders in the Swedish work force is confounded by lifting and posture. J Sound Vib. 2006;298(3):492-8, https://doi.org/10.1016/j.jsv.2006.06.024.

28. Hooftman WE, van der Beek AJ, Bongers PM, van Mechelen $\mathrm{W}$. Is there a gender difference in the effect of work-related physical and psychosocial risk factors on musculoskeletal symptoms and related sickness absence? Scand J Work Environ Health. 2009:35(2):85-95, https://doi.org/10.5271/sjweh.1316.

29. Fillingim RB, King CD, Ribeiro-Dasilva MC, Rahim-Williams B, Riley JL. Sex, gender, and pain: A review of recent clinical and experimental findings. J Pain. 2009:10(5):44785, https://doi.org/10.1016/j.jpain.2008.12.001.

30. Burström L, Järvholm B, Nilsson T, Wahlström J. Back and neck pain due to working in a cold environment: A cross-sectional study of male construction workers. Int Arch Occup Environ Health. 2013;86(7):809-13, https://doi.org/10.1007/ s00420-012-0818-9.

31. Björ O, Damber L, Jonsson H, Nilsson T. A comparison between standard methods and structural nested modelling when bias from a healthy worker survivor effect is suspected: An iron-ore mining cohort study. Occup Environ Med. 2015;72(7):536-42, https://doi.org/10.1136/oemed-20 14-102251.

32. Hauke A, Flintrop J, Brun E, Rugulies R. The impact of workrelated psychosocial stressors on the onset of musculoskeletal disorders in specific body regions: A review and meta-analysis of 54 longitudinal studies. Work Stress. 2011;25(3):243-56, https://doi.org/10.1080/02678373.2011.614069.

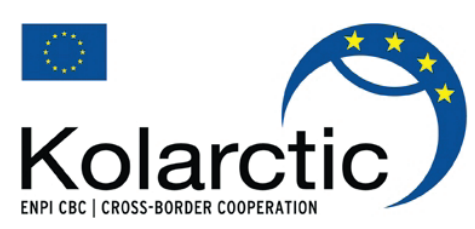

This work is available in Open Access model and licensed under a Creative Commons Attribution-NonCommercial 3.0 Poland License - http://creativecommons.org/ licenses/by-nc/3.0/pl/deed.en. 